\title{
AC 2010-827: PREPARING AND EDUCATING THE QATARI ENGINEER OF 2030
}

Mazen Hasna, Qatar University

Abdelmagid Hamouda, Qatar University

Boualem Boashash, Qatar University 


\title{
Preparing and Educating the Arab Qatari Engineer of 2030
}

\begin{abstract}
This paper addresses the issue of adapting Engineering Education to a changing situation in Qatar, a small country that is part of the Arab Gulf Cooperation Council. It presents the framework for a national project planned to take place in the State of Qatar during the 2010/11 academic year.

Over the past few years, several professional organizations started reviewing the issue of preparing engineers for the future. Examples of these are: "The Engineer of 2020: Visions of Engineering in the New Century", and "Educating the Engineer of 2020: Adapting Engineering Education to the New Century" by the National Academy of Engineering (NAE) in the US, and the "Educating Engineers for the 21st Century" by the Royal Academy of Engineering in the UK. These reports analyzed the changes that are taking place in the engineering profession in order to anticipate how the future will and should look like. Based on that, recommendations for action were given to define the characteristics of the future engineer.

In Qatar, the Qatari government has recently announced the country vision for 2030 (Qatar National Vision 2030, QNV2030). The vision relies on four pillars, namely Human development, economic development, environmental development, and social development. As the economy and development of Qatar relies heavily on oil and gas and as there is an ambitious plan in place to move to a knowledge based economy, it is believed that engineers will need to play a key role in achieving QNV 2030, and that it will be important to take into account some specific characteristics of the Qatari engineering profession, such as the high proportion $(60 \%)$ of female engineers in the College of Engineering of the only National university in Qatar i.e. Qatar University.
\end{abstract}

This paper describes the guiding principles in doing the study, developing the methodologies that will be used and ensuring that the expected outcomes are realized.

\section{Introduction, Perspective and Guiding Principles}

\subsection{Population Size}

According to the latest census, the total population of Qatar is 1.58 millions of which Qatari nationals represent only $20 \%$. Considering the male/female ratio of the population we notice that female constitute only $22 \%$ of the population which reflects the fact that a large ratio of the population is of labor nature. The two major industries in Qatar that attract this kind of labor are the oil and gas, and the construction industries. But, in an apparent paradox,the ratios within the universities in Qatar, we notice that female students are dominant: about 70\% of QU students are females. Even in the College of Engineering, females constitute 60\% of the student population. The reason for this female dominance is that many potential male students decide to join the army after high school while others decide to go for vocational training at the Qatar Petroleum training center or at the college of the North Atlantic which offers two and three years diplomas. In addition, many of the male students who are actually interested in Higher Education choose to go overseas, while for cultural and social reasons, female students prefer to stay closer to home. As a result, engineering schools in Qatar are now graduating more female students than male ones. Due to some of the cultural constraints, the question of fitting females in the workplace has 
generated some discussions locally and as part of this project, there is a plan to address this issue. It is interesting to note that while in Western countries, there is a problem in attracting female students to Engineering, in Qatar and most Arab countries, it is the exact opposite.

\subsection{Carbon Based or Knowledge Based Economy}

The economy of Qatar is one of the largest growing economies worldwide. The GDP has grown more than $11 \%$ over the past few years and oil and gas account for more than $50 \%$ of it. In fact, Qatar has about $15 \%$ of the world natural gas reserve and is scheduled to produce about $30 \%$ of the world's natural gas by 2012. To avoid too much depency on one sole sector, the new QNV 2030 includes an ambitious plan to develop a knowledge based economy in preparation for the post carbon era. The role of engineers in all of this is critical; projections indicate that this role will evolve over the next few years to run and manage the huge industrial plants being built, to acquire and retain the new technologies being implemented, and to have enough innovations to create opportunities in a dynamic and changing economy. This research project aims to address the key problem of adapting the Qatari engineer formation to the needs described above.

\subsection{Accreditation}

Accreditation is an important component for professional degrees. Efforts to identify the necessary educational preparation for engineering practice in the US for example goes back in history to 1907 where the society for the promotion of engineering education in coordination with several engineering professional societies conducted a study on educational requirements for different disciplines, and was published in the Mann report . In 1930, another study initiated by the same society produced the Wickenden report that compared engineering education in the United States and Europe. One of the key recommendations of this report was the need to establish an organization to set standards for engineering educational programs and to conduct reviews of compliance with standards. This has resulted later in the establishment of ECPD, the Engineers Council for Professional development, and which became later the leading American accreditation body for engineering, technology, computing and applied sciences, namely ABET (Prados 2007).

ABET accreditation is highly sought in Qatar and the region. The college of engineering at QU received substantial equivalency accreditation from ABET in 2005 for four of its programs. While other accreditation bodies exist around the world, ABET accreditation is expected to stay dominant in the near future due to the dominance of the American-like curricula in the region, the expertise that accumulated over the years in its procedures and processes, and the increasing competition in the area that forced the universities to look for external benchmarking in terms of programs and institutional accreditations. Hence, accreditation requirements should be addressed in any suggested changes or modifications as significant constraints, taking into account the paradox that following ABET requirements is part of a globalization process with American leadership, while focusing on local needs and constraints require to move away from this process.

\subsection{Use of Technology}

Technology is an important factor in advancing peoples lives and hence many studies took place to assess the effect of technology on different aspect of human beings, including in the area of learning. For higher education in particular, technology has helped in many aspects. To name few examples, delivery of courses is more interactive and efficient, especially using content 
management systems like blackboard (which is currently mandatory to use at QU). Simulation packages have helped in reducing experiments time and exposing students to situations that were not possible or difficult otherwise; and fast computing helped in solving problems that were almost impossible in the past. In addition, technology has helped introduce new pedagogies and shift the education process to become more students' centered with moving the role of the teacher to more of facilitating and educating students on how to acquire knowledge. Technology will continue to be an important factor that affects education in general, and especially engineering education. Recently, the horizon report (Johnson 2009) has identified few technologies that are expected to affect educational institutions on the short and long term. The report will be thoroughly reviewed as part of this project, and its effect on engineering education in Qatar will be fully investigated.

\subsection{QNV 2030}

One of the key guiding perspectives of this project is QNV2030, as mentioned earlier; it presents a big challenge to educational institutes i.e. to graduate citizens that are able to achieve the country vision. More details about the pillars of the vision and the role of engineers in achieving them are given in subsequent sections.

\section{Stakeholders}

In addition to the authors of this paper who are the project key investigators, the following are expected to be the major partners of this project:

1- General Secretariat of Development Planning (GSDP): This is the entity responsible for setting the strategies to achieve the QNV2030. Interaction with this entity is a key to the success of the project. GSDP was very supportive recently to Qatar University college of engineering in establishing a new research center that focuses on innovations in wireless communications.

2- Major industries in Qatar: These include: Qatar Petroleum, Ras Gas, Qatar Gas, and others. It is important to involve major industrial players in Qatar in various steps of the project. The type of involvement will be through focused groups and targeted workshops to get feedback on their future plans for expansions and their views on the evolving roles of engineers and the different set of skills and technical competencies that are expected in the future. Most of the major industrial players in Qatar are currently sponsoring research centers and chair positions in the QU college of engineering and hence an open channel with them exists already.

3- Society of Qatari Engineers: It was established in 2006 with a role to advance and support the profession of engineering. Even though the society is in its infancy stage, they will help in playing a role with engineers after graduation in terms of career advancement and continuous education. An important topic of interest to the society of engineers and this project is the current discussion about licensing in Qatar as a means to ensure lifelong learning and maintain up to date technical competencies. The society confirmed in writing that it is highly supportive of this project.

4- Qatarization Committee in the energy and industry sector: this is an important Qatari national committee that promotes different activities to attract nationals to get educated and then work in the energy and industry sector. Being the dominant sector, there is a 
need for Qatari nationals to be the core working force there from a knowledge transfer point of view as well as from a simple national security perspective. The committee has been active in supporting studies tackling the importance of energy jobs (mainly engineering) and advancing and retaining those who are already working in the sector. The committee is expected to play a partner role in this project and has provided a support letter to this project

5- International organizations on engineering education: As part of this project, representatives from international engineering organizations will be involved as consultants. Experts from the national academy of engineers as well as the royal engineering academy who developed similar studies in their regions will be selected. They will then be invited to share their experience and methodologies used as well as the challenges faced during their own studies, so that the proposed project avoids previous mistakes and reaches efficiently the desired outcomes.

\section{Methodologies}

\subsection{Aims}

The proposed research project focus will include a study about the development of attributes and characteristics of future Engineers in Qatar Educational System. Specifically, this projectaims to:

1- assess the current status of Engineering Education in Qatar,

2- review international best practice.

3- define the attributes of the ideal Qatari engineer of the future,

4- perform a gap analysis between the findings of 1 and 2, and between 1 and 3, and

5- make recommendations for implementation to make necessary changes to narrow or eliminate the identified gaps, and when possible start the implementation process as a pilot project.

The proposed research project will take an integrated team approach to treat this interdisciplinary subject. We assembled an interdisciplinary team of administrators/researchers from college of engineering, Qatar University to deal with the different facets of this project.

To effectively manage the different aspects of the research, we have grouped the above mentioned objectives into three highly coupled themes (I, II and III). The work in these themes, which is summarized below, will be conducted concurrently with seamless exchange of data between them.

1- Theme I: Engineering Education in Qatar, Regional and Global trends.

2- Theme II: Engineer of 2030

3- Theme III: Pilot Implementation in the College of Engineering, Qatar University

The methodological framework that will be used in this research project is a mix of two approaches: 1) the Delphi Method and 2) the Scenario-based method. Each method has a specific functionality and assumptions. The aim will be to join together the strong points of each method, as well as to replace the deficiencies that are present when they work in isolation. 


\subsection{Approach 1: the Delphi Technique:}

a) Technique description.

The Delphi approach consists of a survey conducted in three rounds and provides the participants in the second round with the results of the first so that they can alter the original assessments if they want to - or stick to their previous opinion. Nobody 'looses face' because the survey is done anonymously using a questionnaire (the first Delphi's were panels). The Delphi method is especially useful for long-range forecasting (20-30 years), as expert opinions are the only source of information available. During the last ten years, the Delphi method was used more often especially for national science and technology foresight (Gordon, T. \& Pease, A., 2006). Since the Delphi method relies on expert opinion provided by panels, it is obviously important to select the right experts. In some cases, Delphi participants are selected through a "nomination" process in which recognized experts are solicited but also asked to provide the names of other experts. Selection criteria should be clearly articulated, e.g. number of years of experience, number of publications or other expert qualifications.

b) The Delphi Process

The study requires three rounds of surveys. Round one generates an initial list of student learning benchmarks for each content area. Round two requires each panel member to rate each item generated in Round one and allows panel member to add new items. Consensus is defined as a standard deviation <1.0. Items for which consensus is not reached in Round two are sent out again in Round three. Consensus is reached on all items for all six content areas in Round three. See Figure 1 for a graphic depiction of the process used.

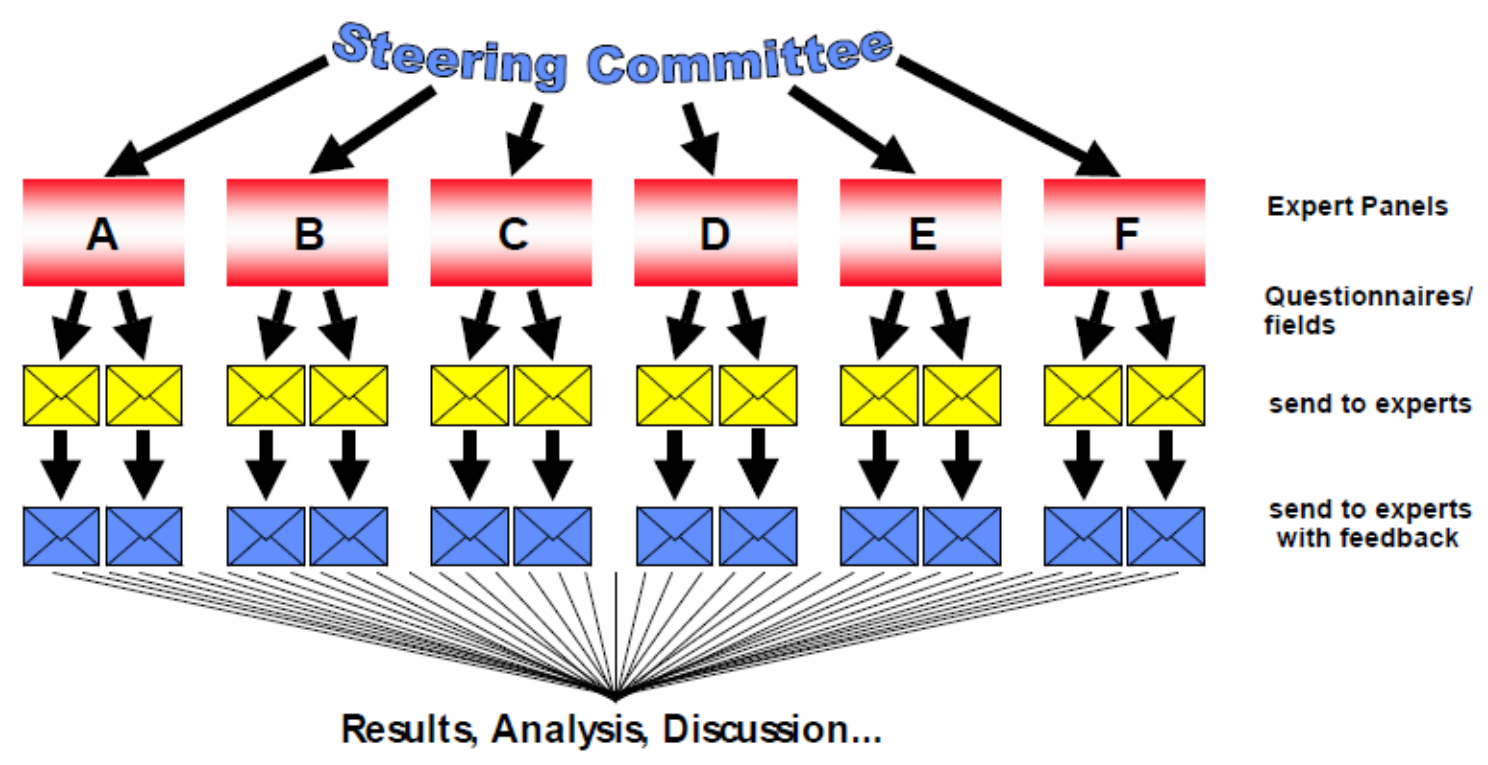

2002)

Figure 1: Organization of the Delphi Method (Cuhls, K; Blind, Knut G, H, 


\subsection{Approach 2: Scenario Based}

a) Technique Description.

A number of series of focused workshops will be organized and managed by the research team in collaboration with our local collaborators and other stakeholders (e.g. Qatar Petroleum, Qatari Society of Engineers, Qatar Foundation -Education City, Supreme Education Council, and General Secretariat for Development Planning, among others). Workshop participation will be by invitation and carefully selected. The workshop attendees will represent all the sectors involved in engineering education in Qatar. The workshops will be moderated by International Experts (consultant) together with the research team and some members from our collaborators. Scenario based tools will be used in this research project to get the perceptions from the workshop attendees about future environments. Scenario planning is a highly interactive process that is intense and imaginative. The idea of scenarios is to tell possible stories about the future. The initial phase usually involves rigorously challenging the mental maps that shape one's perceptions [Chermack, 2004].

b) The Process:

In the body of the process, groups identify driving forces (social, economic, political, and technological) and the factors that shape those forces. These factors are then prioritized according to importance and uncertainty.

Why use scenario planning as a way to determine the Qatari Engineering Education 2030? In uncertain times, a structured stakeholder dialogue can provide valuable insights into how the future might unfold for an organization. Because of stakeholder involvement, even unpleasant futures can be accepted as plausible, allowing the organization to become aligned around facing and planning for them [Banuls and Salmeron, 2007].

\section{Expected outcomes}

The study will also identify and analyze the curricular, pedagogical, cultural, and organizational features of engineering education programs in Qatar. So, the expected outcomes from this study will include the following:

1. A revised list of the Technical knowledge (Competences) needed, such as i) Basic Sciences (Mathematics, physics, chemistry, biology, mechanics and materials) (ii) Design; (iii) Sustainability; (iv) Business and Finance; (v) Social Sciences and (vi) Ethical Behavior

2. A revised list of the Skills neede; this will include (i) Problem-solving skills; (ii) Apply Basic Engineering Tools (iii) Usage and Master New Technology (iv) Communication; (v) Managing Risk and Leadership. This will include the abilities to understand the constraints and impacts of social, cultural, environmental, political, and other contexts on engineering solutions.

3. A revised list of attributes: Creativity and Entrepreneurship (ii) Innovation and integration (iii) Commitment (iv) Honesty and Integrity (v) Respect and Tolerance (vi) Thoroughness and Self-Discipline. 


\section{Conclusions}

This paper presented the general framework for a project for reforming engineering education in the State of Qatar. The outcomes of the project are expected to play a key role in shaping the future of engineering education in Qatar and to enhance the efforts that target the introduction of engineering topics in basic education levels (k-12). The outcomes of this project will lead to a better definition and description of the ideal Arab Qatari, and a refinement of the formation process that produces such Engineers so that they balance the rigor of recognized international best practice with the cultural and social constraints of the Arab Qatari society.

\section{References}

Banuls, V.A and Salmeron, J.L. (2007). A Scenario-Based Assessment Model—SBAM, Technological Forecasting \& Social Change 74, 750-762.

Chermack, T.J. (2004). Improving decision-making with scenario planning, Futures 36 (3) 295309.

Cuhls, Kerstin; Blind, Knut und Grupp, Hariolf (2002). Innovations for our Future. Delphi '98: New Foresight on Science and Technology. Technology, Innovation and Policy, Series of the Fraunhofer Institute for Systems and Innovation Research ISI no. 13. Physica Heidelberg, pp.15ff.

Ellis H J C (2006) Self-grading: an approach to supporting self-directed learning. SIGCSE Bull 38: $349-349$

Freitas S d, Harrison I, Magoulas G, Mee A, Mohamad F, Oliver M, Papamarkos G, Poulovassilis A (2006) The development of a system for supporting the lifelong learner. Brit J of Ed Tech 37: 867-880

General Secretariat of Development Planning GSDP (2008) "Qatar National Vision" available at http://www.gsdp.gov.qa/portal/page/portal/GSDP_Vision_Root/GSDP_EN/GSDP_News/GSDP \%20News\%20Files/QNV2030_English.pdf, July.

Gordon, T. \& Pease, A.(2006). RT Delphi: An efficient "round-less" almost real time Delphi method. Technological Forecasting and Social change 73: 321-333.

Johnson, L., Levine, A., \& Smith, R. (2009). The 2009 Horizon Report. Austin, Texas: The New Media Consortium.

National Academy of Engineering (2004). The Engineer of 2020: Visions of Engineering in the New Century, National Academy of Engineering Press.

National Academy of Engineering (2005). Educating the Engineer of 2020 - Adapting Engineering Education to the New Century, The National Academies Press. 
National Science Board (2007). Moving Forward to Improve Engineering Education, National Science Foundation.

Prados, J (2007) “A Proud Legacy of Quality Assurance in the Preparation of Technical Professionals: ABET 75th Anniversary Retrospective"

Royal Academy of Engineering (2007). Educating Engineers for the 21st Century. http://www.raeng.org.uk/education/ee21c/default.htm

Supreme Education Council web site www.english.education.gov.qa

Steffens, K. (2006). Self-regulated learning in technology enhanced learning environments: lessons of a European peer review. European Journal of Education,41 (3/4), 353- 414.

Vollmeyer R and Rheinberg F (2006) Motivational Effects on Self-Regulated Learning with Different Tasks. Educ Psychol Rev 18: 239-253

Wang F, Hannafin M (2005) Design-based research and technology-enhanced learning environments. Ed Tech R\&D 53: 5-23

Wang F, Hannafin M J (2005) Design-Based Research and Technology-Enhanced Learning Environments. ETR\&D 53: 5-23

Zimmerman, B.J. (2000). Attaining self-regulation: a social cognitive perspective. Pp. 13- 39 in M. Boekaerts, P. Pintrich, \& M. Zeidner (Eds.). Handbook of Self-Regulation. New York: Academic Press. 